\title{
Contributiones ad studia monographica Geoglossacearum
}

\author{
auctore
}

\section{Sanshi Imai}

Received September 1st. 1942.

I. Novae species

\section{Microglossum Rickii ImaI.}

Geoglossum viride (non Pers.) RICK, Broteria, ser. Bot. XXV, 73, 1931. Microglossum Ricki ImaI, Jour. Facul. Agr. Hokkaido Imp. Univ. XLV, 183, 1941, nom. nud.

Ascomatibus saepe fasciculatis, siccate $3-4 \mathrm{~cm}$. longis; clavulis siccate $0.7-1.5 \mathrm{~cm}$. longis et $2-4 \mathrm{~mm}$. latis, $1 / 5-1 / 3$ ascomatae loculis, a stipite bene distinctis, glabris, olivaceo-viridis, elongatis ; stipitibus cylindraceis, aequalibus, siccate 1-2 mm. crassis, squamulosis, magis viridis quam clavula; ascis clavatis vel clavato-cylindraceis, apice obtusis, membrana crassis, poro iodo caerulescentibus, $65-75 \times 9-10 \mu$, octosporis; sporis supernus subdistichis infernus monostichis, ellipsoideis vel brevi-fusiformibus, utrinque acutis vel obtusiculis, rectis vel subcurvatis, longe continuis, dein 1-3-septatis, hyalinis, 10-14×4.5-5 $\mu$; paraphysibus filiformibus, ramosis, hyalinis, apicibus subpiriforme vel subcapitate incrassatis et viridescentibus.

Hab. in graminosis inter arbusta.

Typus in Herb. ImaI.

Loc. typ. : Novo Petropolis, Brasilia.

Area distr.: Endemicum.

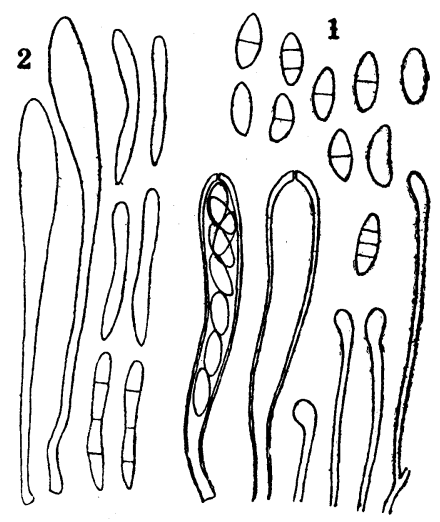

Fig. 1. Microglossum Rickii ImaI.

$$
\begin{aligned}
2 & \text { asci } \times \text { ca. } 500 \\
10 & \text { sporae } \times \text { ca. } 500 \\
4 & \text { paraphyses } \times \text { ca. } 500
\end{aligned}
$$

Fig. 2. Cudonia spathulata ImaI.

$$
\begin{array}{lll}
2 \text { asci } \times \text { ca. } & 500 \\
6 \text { sporae } \times \text { ca. } & 660
\end{array}
$$


Exempl. invest. :

America austr.-Brasilia : Novo Petropolis (J. RICK, 1923) (ex Farlow Herb.).

Species haec a Microglossum viride differt ascis sporisque minoribus et stipite magis viridi quam clavula.

\section{Cudonia spathulata ImaI.}

Ascomatibus gregariis, siccate usque ad $3 \mathrm{~cm}$. longis, subcapitatis vel subspathulatis, stipitatis, carnosis; pileis irregulare subcapitatis vel lateralle compressis, rugosis, subplicato-sulcatis vel undulatis, siccate "ochraceousbuff", "orange-cinnamon" vel "umber-brown", 0.5-1.2 cm. latis ; stipitibus subaequalibus vel sursum leviter attenuatis, basi saepe attenuatis, rugulosis, siccate "light buff", "warm buff", "cinnamon-buff" vel "cinnamon"; ascis clavatis, basi admosum longe attenuatis, apice contractis, poro iodo non caerulescentibus, $90-110 \times 7.5 \mu$; sporis subcylindraceis vel leviter clavatofiliformibus vel acicularibus sed medio leviter constrictis, hyalinis, fasciculatis, $17.5-24 \times 2 \mu$; paraphysibus filiformibus, tenuissimis, hyalinis, ramosis, apicibus vix incrassatis, curvatis vel circinatis.

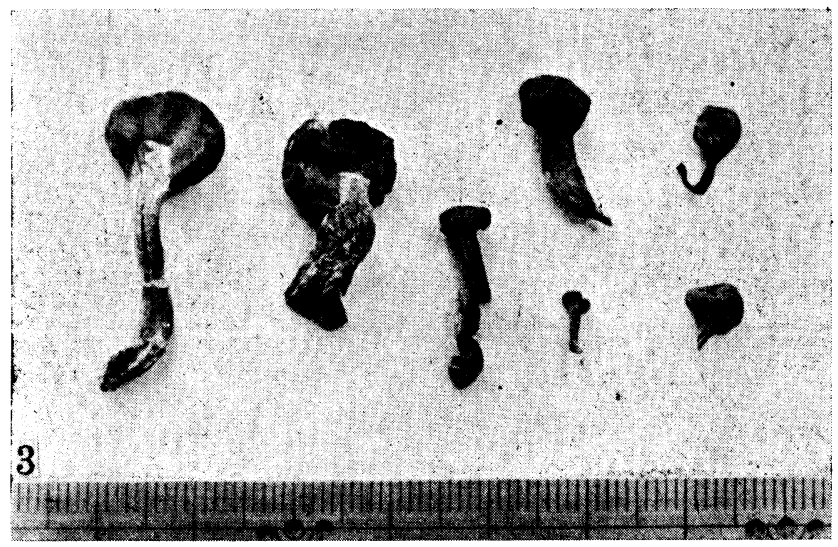

Fig. 3. Cudonia spathulata ImaI. $\times$ ca. 1/1

Hab. ad terram.

Typus in Herb. Univ. California, America bor. (No. 439652).

Loc. typ. : Big Basin, Calif., America bor.

Area distr. : Endemica.

Exempl. invest. :

America bor.-California: Big. Basin (H. E. Balley, Feb. 22, 1931).

II. Nova genera.

\section{Leucoglossum Imai.}

Ascoma carnosum?, siccum, erectum, stipitatum, clavatum vel lanceo- 
latum, sursum ascigerens, albidum. Asci clavati, inoperculati, octospori; sporae multiseriatae, hyalinae, 6-15-septatae, cylindraceo-clavatae?; paraphyses filiformes?, subhyalinae; cystidia in clavulam stipitemque praesentia, atra vel atro-brunnea?, acicularia.

Typus : Trichoglossum Durandii Teng.

Genus hoc monotypicum et sporis hyalinis notabilis est. Species typica Leucoglossum Durandii (TENG) IMAI nominatur.

\section{Bagnisimitrula ImaI.}

Ascoma rectum, stipitatum, capitatum; clavula globoso-ovoidea, crassa. Asci lineari-clavati, octospori; sporae hyalino-vinosae, asperulatae.

Typus : Mitrula Saccardoa BAgNis.

Genus hoc a Mitrula Fr. sensu auctoris et Gymnomitrula ImaI differt sporis vinoso-coloratis et asperulatis. Species typica Bagnisimitrula Saccardoa (BAGNIS) IMAI nominatur.

III. Novae combinationes.

\section{Scleromitrula Brassicae (HAMmerL.) ImaI.}

Mitrula Brassicae Hammerl. Ark. f. Bot. XXVA, 3, 59, 1932-Nannf. Ark. f. Bot. XXXA, 4, 49, 1942.

Hab. ad folia Brassicae oleraceae f. capitatae.

Area distr.: Europa (Swecia: Bunkeflo).

\section{Cibarocoryne Peckiana (Cke.) ImaI.}

Geoglossum difforme Fr. Syst. Myc. I, 489, 1821, p. p. teste NannF.

Geoglossum Peckianum Cke. Hedw. XIV, 10, 1875-Nannf. Ark. f. Bot. XXXA, 4, 38, 1942.

Gloeoglossum difforme Durand, Ann. Myc. VI, 421, 1908.

Hab. ad terram in silvis.

Area distr.: Europa, America bor., Asia orient.

3. Cibarocoryne glutinosa (Pers. ex Fr.) ImaI.

Geoglossum glutinosum Pers. Obs. Myc. I, 11, 1796-Fr. Syst. Myc. I, 489, 1821.

Geoglossum glutinosum $\beta$ lubricum Pers. Myc. Eur. I, 197, 1822.

Geoglossum Mulleri Berk. in CKe. Mycogr. I, 4, t. 1, f. 2, 1875.

Cibarocoryne visculosa HazsL. Mag. Tudom. Akad. Ert. A Termés-tud. Kör. XI, 19, 8, 1881, teste NANNF.

Geoglossum visculosum Sacc. Syll. Fung. VIII, 43, 1889.

Gloeoglossum glutinosum Durand, Ann. Myc. VI, 419, 1908.

Hab. ad terram in silvis.

Area distr.: Europa, America bor., Asia orient., Australia. 
4. Cibarocoryne affinis (Durand) ImaI.

Gloeoglossum affine Durand, Ann. Myc. VI, 420, 1908.

Geoglossum affine SACc. et Trotт. in SACC. Syll. Fung. XXII, 606, 1913. Hab. ad terram.

Area distr.: America borealis.

5. Cibarocoryne Barlae (Boud.) ImaI.

Geoglossum Barlae Boud. Bull. Soc. Myc. Fr. IV, 76, 1888.

Geoglossum Peckianum f. Barlae Mass. Ann. Bot. XI, 251, 1897.

Hab. ad terram argillosam.

Area distr.: Europa.

6. Cibarocoryne bogoriensis (P. Henn. et Nym.) ImaI.

Geoglossum bogorieñse P. HENN. et E. NYM. Monsunia I, 36, 1899, ex diagn.

Hab. ad terram.

Area distr. : Asia trop.

Instituto Botanico,

Facultas Agricultura,

Universitas Imperialis Hokkaidensis,

Sapporo, Japonia.

\section{てんぐのめしがひ科ノ集成的研究ニ對スル寄與}

$$
\text { 今 井 三 子 }
$$

I. 新種

1. Microglossum Rickii ImaI.

Brasil ノ Riogrand 地方產昇龍菌目二就イテノ RICK 氏ノ報告中= Microglossum viride トシテ報告サレタ菌ノ標品ヨ調查シテミルト，菌柄ノ性質卜子囊及ビ胞子ノ 大イサニ相違ガ認メラレルノデ, 新種トシタ。M. viride 八菌柄ヨリ頭部ノ方ガ暗綠 色ガ濃厚デアルノ， Brasil ノ菌八菌柄ノ方ガ綠色ガ濃厚デアリ, 又子囊入 Brasil ノ菌ガホ形デソノ膜ガ厚ク，胞子モ亦小形デアル。

2. Cudonia spathulata IмаI.

先年, 北米，California 大學カラ同地方固有種) Cudonia ochroleuca (CKE. et HARKN.) DUFAND ト同定シテオルト標品习借覽シタ際ニ, ソノ內ノ 1 標品ハ明カ二 別種デアルノヨ.認メタノデ, 新名ヨ附シテ報告シタ。外形八一見, Spathularia ト Cudonia) 中間形デアルガ, ソノ顯微鏡的性質入Cudonia / section Pachycudonia = 屬スルモノデアル。同大學カラ借覽シタ標品ノ他ノ 1 ツ, Cudonia ochroleuca ト 
八全ク別種デ，明カ二新種デアツタガ，乾燥標本ナノデ，報告ヨ差控ヘテオツタ所， 之卜同一種卜思ハレルモノタ，昨 1941 年北米 Michigan 大學) MAINs 敎授ガ, Cudonia monticola MAINS トシテ報告シタ。

II. 新屬

1. Leucoglossum IMar.

支那/南京地方カラ, 鄧氏ガ Trichoglossum Durandii TENG トシテ報告シタ種類 八，胞子ガ無色デアルト記載シテキル。之レハTrichoglossum 二屬スルモノデナク， 别屬ヨ作ルベキモノデアル。

2. Bagnisimitrula IMAI.

伊太利カラ, Mitrula Saccardoa BAGNIS トシテ報告サレタ種類八，胞子ガ葡萄色 ヨ交ヘテオリ，表面二微刺ヨ有シテオルト云フカラ全ク別屬ニ入ルベキデアル。

III. 新 組 合

1. Scleromitrula Brassicae (HammerL.) ImaI.

瑞典カラ甘藍〉葉二寄生シ; 菌核ヨ作ル Mitrula Brassicae HAMMERL. ガ報告サレ 夕。菌核ヨ作儿性質カラ, 之八上記ノ屬ニ移サレネバナラナイ。

2. Cibarocoryne Peckiana (CKE.) IMaI. まつばしやもじれけ

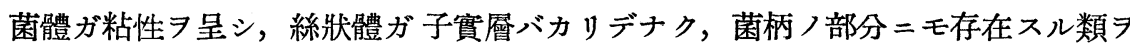
Gloeoglossum DuRand (1908) 屬 二入レテオツタガ，1881 年二既ニハンカリー， HAZSLINSZKI氏ガ報告シタ Cibarocoryne visculosa n. g. et n. sp. 八, 今日ノGloeoglossum glutinosum (PERS. ex Fr.) DUR. ト同一種デアルコトガ判明シタ。從ツテ屬名 八Cibarocoryne ヨ用ヒネバナラヌコトニナル，ソコデ以下ノ改名ガ必要ニナツテ 來儿。C.Peckiana 八DURAnd 氏ノ意見 $=\exists ル G l$ difforme (Fr.) Dur. ト同一デア ル。本年 (1942) 瑞典 Uppsala ノBotanical Museum ノNANNFELDT 教授八 Fries 氏 ノ標品及ビ記事カラ Geoglossum difforme Fr. ヨ用フルョリモ, G. Peckianum CKE. ヨ探用スル方ガ合理的デアルト報告シタ。從ツテ今包入之レニ從フコトニシタ。

3. Cibarocoryne glutinosa (PeRs. ex Fr.) IMAI. ときわしやもじたけ

4. C. affinis (DURAND) ImaI.

5. C. Barlae (Boud.) ImaI.

6. C. bogoriensis (P. Henn. et Nym.) Imai. 